\title{
Dynamics of cytoplasm and cleavage divisions correlates with preimplantation embryo development
}

\author{
Robert Milewski ${ }^{1}$ Marcin Szpila² and Anna Ajduk ${ }^{2}$ \\ ${ }^{1}$ Department of Statistics and Medical Informatics, Medical University of Bialystok, Bialystok, Poland and \\ ${ }^{2}$ Department of Embryology, Faculty of Biology, University of Warsaw, Warsaw, Poland \\ Correspondence should be addressed to A Ajduk; Email: aajduk@biol.uw.edu.pl
}

\begin{abstract}
In vitro fertilization has become increasingly popular as an infertility treatment. In order to improve efficiency of this procedure, there is a strong need for a refinement of existing embryo assessment methods and development of novel, robust and non-invasive selection protocols. Studies conducted on animal models can be extremely helpful here, as they allow for more extensive research on the potential biomarkers of embryo quality. In the present paper, we subjected mouse embryos to non-invasive time-lapse imaging and combined the Particle Image Velocimetry analysis of cytoplasmic dynamics in freshly fertilized oocytes with the morphokinetic analysis of recordings covering 5 days of preimplantation development. Our results indicate that parameters describing cytoplasmic dynamics and cleavage divisions independently correspond to mouse embryo's capacity to form a high-quality blastocyst. We also showed for the first time that these parameters are associated with the percentage of abnormal embryonic cells with fragmented nuclei and with embryo's ability to form primitive endoderm, one of the cell lineages differentiated during preimplantation development. Finally, we present a model that links selected cytoplasmic and morphokinetic parameters reflecting frequency of fertilization-induced $\mathrm{Ca}^{2+}$-oscillations and timing of 4-cell stage and compaction with viability of the embryo assessed as the total number of cells at the end of its preimplantation development. Our results indicate that a combined analysis of cytoplasmic dynamics and morphokinetics may facilitate the assessment of embryo's ability to form high-quality blastocysts.
\end{abstract}

Reproduction (2018) 155 1-14

\section{Introduction}

In vitro fertilization (IVF) is currently one of the most important methods for treating infertility. In spite of a great advancement in IVF procedures that took place in the last decades, their efficiency, measured as a live birth rate per cycle, reaches $50 \%$ in young patients, but is several times lower in older patients (e.g. in the US in 2014, a cumulative outcome per egg retrieval cycle, including transfers performed with fresh and frozen embryos, was $54.4 \%$ for women younger than 35 years old but only $3.9 \%$ for women older than 42 years old, according to Society of Assisted Reproductive Technologies (SART), www.sart.org). To increase the chances for pregnancy, multiple embryos can be transferred in a single procedure, but this often results in multiple pregnancies, and, in consequence, in serious health complications for mothers and their babies (Walker et al. 2004, Ombelet et al. 2005). Therefore, there is a strong tendency to limit the number of embryos transferred in a single cycle. This in turn puts a constant pressure on scientists and physicians to develop novel, reliable methods of selecting the most viable embryos for transfer.
One of the most promising methods used to assess embryo's quality, defined usually as its ability either to develop to the blastocyst stage or to implant and give rise to a healthy newborn, is the morphokinetic analysis based on a time-lapse imaging of preimplantation embryonic development. Morphokinetic parameters include absolute timings of blastomere divisions and main morphological events, such as compaction and cavitation, as well as relative timings, such as length of a cell cycle and synchronicity of divisions in each cleavage round. Dynamics of cleavage divisions reflects most likely quality of nuclear and cytoplasmic components of the embryo (reviewed in Ajduk \& Zernicka-Goetz (2013) and Milewski \& Ajduk (2017)). It has been reported that IVF cycles, in which time-lapse monitoring was used to select transferred embryos, have a significantly better reproductive outcome (e.g. implantation and pregnancy rates) than cycles, in which traditional morphology assessment was applied (Meseguer et al. 2012, Aparicio et al. 2013, Herrero \& Meseguer 2013, Findikli \& Oral 2014, Rubio et al. 2014, Siristatidis et al. 2015, AparicioRuiz et al. 2016). However, others claim that although morphokinetic parameters can predict embryo potential to achieve a blastocyst stage, their analysis increases neither implantation nor pregnancy rate (Cruz et al. 2011, 
Kirkegaard et al. 2013, 2015, Polanski et al. 2014, de los Santos et al. 2014, Armstrong et al. 2015, Racowsky et al. 2015, Ahlstrom et al. 2016, Goodman et al. 2016, Kieslinger et al. 2016). This dispute indicates that there is a strong need for improvement of morphokineticsbased embryo assessment protocols. One of the possible solutions is to combine the morphokinetic analysis with other biomarkers of embryonic quality.

Cytoplasmic dynamics in freshly fertilized oocytes is a good example of a potential additional biomarker. It can be visualized, similarly to morphokinetics, by timelapse monitoring, but obtained images require further analysis by a Particle Image Velocimetry (PIV) algorithm that follows movement of amorphous objects, such as cytoplasm (Ajduk et al. 2011). Fertilization-induced $\mathrm{Ca}^{2+}$ oscillations trigger rhythmic actomyosin-mediated spasms that translate to fast directional cytoplasmic movements (so called speed-peaks). The spasms last only for several hours after fertilization, until pronuclei are formed (Ajduk et al. 2011). Similar pattern of cytoplasmic movements has been also reported for human oocytes (Swann et al. 2012). Analysis of cytoplasmic dynamics provides information on functionality of the zygote cytoskeleton, especially its actomyosin component (reflected by the mean basal speed (mbs), i.e. mean cytoplasmic speed in periods between the speed-peaks), and on the frequency of $\mathrm{Ca}^{2+}$ oscillations (reflected by the mean inter-peak interval (mii), i.e. mean length of time intervals between the subsequent speed-peaks). Both these properties are crucial for a proper embryonic development, with actomyosin cytoskeleton responsible for organelle trafficking and cellular divisions, and $\mathrm{Ca}^{2+}$ transients serving as a trigger for completion of meiosis, initiation of mitotic divisions, zona pellucida-mediated block to polyspermy and as a regulator of mitochondrial activity and gene expression in the embryos (Dumollard et al. 2004, Ozil et al. 2005, 2006, Campbell \& Swann 2006, Ducibella et al. 2006, Sun \& Schatten 2006, D'Avino et al. 2015). It has been shown that cytoplasmic dynamics corresponds to developmental potential of mouse embryos (Ajduk et al. 2011).

In the present paper, we wished to examine correlations between developmental potential of mammalian embryos and variable parameters obtained solely from the information provided by non-invasive time-lapse imaging. Our imaging protocol combines the PIV analysis of cytoplasmic dynamics in freshly fertilized oocytes and the morphokinetic analysis of recordings covering the 5-day period of the preimplantation development. At the end point, we wished to examine not only embryos' ability to cavitate, but also quality of the resulting blastocysts, i.e., the total number of cells, proportion of cells with fragmented nuclei (most likely apoptotic cells (Martelli et al. 2001, Vanden Berghe et al. 2013)) and percentage of cells representing the first-embryonic cell linages building the blastocyst (epiblast (EPI), trophoblast (TE) and primitive endoderm (PE); reviewed in
Zernicka-Goetz et al. (2009) and Cockburn \& Rossant (2010)), and therefore we used mouse embryos as a model. This approach was particularly important because, until now, there have been no data on the association between cytoplasmic or morphokinetic parameters and embryo's ability to form the first-cell lineages requisite for the further, postimplantation development. We showed that cytoplasmic parameters (the mbs and the mii) and morphokinetic parameters correspond independently to a mouse embryo's capacity to form a high-quality blastocyst, specifically to the total number of cells in a 5-day-old embryo, the percentage of abnormal cells with fragmented nuclei and a percentage of PE cells. Most importantly, however, we prove that cytoplasmic and morphokinetic parameters can be combined in a multivariate regression model explaining $45 \%$ of variability in the total number of cells in a 5-dayold embryo. Uniqueness of our model lies in the fact that it includes variables reflecting diverse cellular properties known to affect developmental potential of the embryo: pattern of $\mathrm{Ca}^{2+}$ oscillations, quality of nuclear apparatus and functionality of the cytoplasmic component.

\section{Materials and methods}

\section{Animals}

F1 (C57Bl6/Tar $\times$ CBA/Tar) mice were maintained in the Animal Facility of the Faculty of Biology, University of Warsaw at 14:10 light/dark cycle and provided with food and water ad libitum. Animals were sacrificed by cervical dislocation. All experiments were approved by the Local Ethics Committee for Experimentation on Animals no. 1 (Warsaw, Poland) and were performed in compliance with the national regulations.

\section{IVF}

Female mice were superovulated with intraperitoneal injection of $10 \mathrm{IU}$ of pregnant mare serum gonadotrophin (Intervet) followed $48 \mathrm{~h}$ later by $10 \mathrm{IU}$ of human chorionic gonadotrophin (Intervet). $15 \mathrm{~h}$ later, oocytes surrounded by cumulus cells were recovered from oviducts into $100-\mu \mathrm{L}$ droplets of fertilization medium with $5 \mathrm{mg} / \mathrm{mL}$ bovine serum albumin (BSA, SigmaAldrich) (Fraser 1982). Epididymal sperm was isolated from male mice and capacitated in $0.5 \mathrm{~mL}$ of fertilization medium for $1.5-2 \mathrm{~h}$, and then $10 \mu \mathrm{L}$ of sperm suspension was added to the droplets with oocytes. Gametes were co-incubated in $37.5^{\circ} \mathrm{C}$ and $5 \% \mathrm{CO}_{2}$ in air for $2 \mathrm{~h}$ and then oocytes with visible signs of sperm penetration (anaphase bulges, fertilization cones, 2nd polar body forming) were selected for imaging.

\section{Imaging and PIV analysis of cytoplasmic movements}

Cytoplasmic movements in fertilized oocytes were imaged and analysed as described by Ajduk et al. (2011). In short, fertilized oocytes were placed on a glass bottom dish (MatTek) in a 20- $\mu$ L droplet of M2 (M16 buffered with Hepes, Fulton \& Whittingham (1978)) medium covered with mineral oil and 
imaged for $2.5 \mathrm{~h}$ under an inverted microscope (Zeiss Axiovert) at $37.5^{\circ} \mathrm{C}$. High-resolution bright field images (without DIC) from a single equatorial plane were collected by a camera attached to the microscope (Zeiss AxioCam HRm) through a $20 \times$ objective (Zeiss Plan Neofluar 20×/0.5) every 10s (light source: a halogen lamp Hal 100 set at $1.5 \mathrm{~V}$, exposure time: $4 \mathrm{~ms}$, binning $1 \times 1$, image resolution with a co-site sampling: $2600 \times 2060 \mathrm{px})$. Images were analysed by a PIV method using a custom written software (available on request from $\mathrm{Dr}$ Shane Windsor, University of Bristol; Ajduk et al. 2011, Swann et al. 2012) in MATLAB (Mathworks) based on algorithms adapted from MatPIV v1.6.1 (Sveen 2004). Two parameters describing cytoplasmic dynamics were measured: the mbs of the cytoplasm and the mii (Fig. 1A). The mbs was calculated as the average cytoplasmic speed recorded in periods between rapid, directional cytoplasmic movements (i.e. speed peaks). The mii was calculated as an average time interval between speed peaks recorded during the period when the fertilization cone (i.e. a cortical protrusion above the sperm chromatin) was present.

\section{Time-lapse imaging of the preimplantation development and morphokinetic analysis}

Zygotes imaged for the cytoplasmic movements were transferred individually to 9- or 16-well dishes (PrimoVision) and were cultured in 20- $\mu \mathrm{L}$ droplet of KSOM medium (Speciality Media, Merck Millipore) for 5 days. During this period, they were subjected to time-lapse recording (every $10 \mathrm{~min}$ ) under the PrimoVision imaging system enclosed in a standard embryo culture incubator maintaining constant culture conditions $\left(37.5^{\circ} \mathrm{C}, 5 \% \mathrm{CO}_{2}\right.$ in air). Images acquired by PrimoVision software were analysed and morphokinetic parameters were calculated (Fig. 1B). The morphokinetic parameters included: (1) $t_{\text {NEBD }}$ - time between the beginning of insemination and the disappearance of pronuclei in the zygote; (2) $t_{2}$ to $t_{8}$ - periods between the beginning of insemination and the moment when embryo reaches a certain number of cells, e.g. 2 cells for $t_{2}, 3$ cells for $t_{3}$, etc.; (3) $t_{\text {comp }}$ and $t_{\text {cavit }}$ - time between the beginning of insemination and compaction and cavitation, respectively; (4) $\mathrm{m}_{1}$ - duration of the 1 st embryonic M-phase, i.e., period between disappearance of pronuclei and 2-cell stage; (5) $\mathrm{CC}_{2 a, b}$ and $\mathrm{CC}_{3 \mathrm{a}-\mathrm{d}}$ - duration of the cell cycle for 2- or 4-cell stage blastomeres, respectively; (6) $s_{2}$ and $s_{3}$ - synchronicity of 2 nd and $3 \mathrm{rd}$ rounds of cleavage divisions, respectively; (7) $\mathrm{s}_{\text {cavit }}-\mathrm{a}$ period between compaction and cavitation.

\section{Immunofluorescence staining}

After 5 days of in vitro culture, embryos were fixed individually in $4 \%$ PFA (30 min, RT), permeabilized with $0.5 \%$ Triton-X100 (30 min, RT) and blocked with 3\% BSA. CDX2, a TE marker, was labelled with mouse monoclonal antibody (1:50, BioGenex, Fremont, CA, USA) followed by a TRITC-conjugated goat antimouse IgG (1:200; Jackson ImmunoResearch Laboratories), and GATA4, a PE marker - with rabbit polyclonal antibody (1:100; Santa Cruz Biotechnology) followed by an Alexa-633conjugated goat anti-rabbit IgG (1:200; Life Technologies). Embryos were incubated in a mix of primary antibodies overnight in $4^{\circ} \mathrm{C}$, washed in PBS and $3 \%$ BSA and then incubated in a mix of secondary antibodies for $2 \mathrm{~h}$ in RT. DNA was stained with chromomycin A3 $(0.01 \mathrm{mg} / \mathrm{mL}$ in PBS; Sigma-Aldrich; $30 \mathrm{~min}, \mathrm{RT}$ or overnight, $4^{\circ} \mathrm{C}$ ). Embryos were analysed by an inverted confocal microscope (Zeiss 510 LSM Meta) (Fig. 1C). Cell numbers were calculated manually in Fiji software.

\section{Statistical analysis}

Nominal variables were compared by the chi-squared test with Yates' correction. For numerical variables, normality of distribution was verified by the Shapiro-Wilk test. As the distribution of analysed parameters was not normal, we used the median and quartiles as estimates of their central tendency and dispersion. Differences between two groups were assessed by the non-parametric Mann-Whitney $U$ test, and differences between multiple (more than two) groups were assessed by the Kruskal-Wallis test. Spearman's rank correlation coefficient was used to show correlations between analysed numerical variables. Univariate and multivariate logistic regression analyses were conducted to assess the influence of cytoplasmic and morphokinetic parameters on embryo ability to achieve a blastocyst stage. In the case of numerically dependent variables (the total cell number in the embryo after 5-day culture, the percentage of cells with fragmented nuclei in the embryo after 5-day culture and the percentage of PE, EPI and TE cells in the $\geq 64$-cell embryo after 5 -day culture), univariate and multivariate linear regression analyses were performed. Statistical significance was determined at the $P<0.05$ level. Statistical inference was conducted using Stata/IC 12.0 (Stata Corp. LP.) and Statistica 12.0 (StatSoft).

\section{Results}

In order to create a model associating preimplantation developmental potential of a mouse embryo with parameters reflecting dynamics of cellular processes, we combined two types of time-lapse imaging-based approaches: analysis of cytoplasmic movements and morphokinetics. We correlated analysed parameters with embryo's ability to cavitate, its total number of cells and proportions of cells with fragmented nuclei and cells expressing markers of the first-embryonic cell linages (TE, EPI and PE) (Fig. 1). In these experiments, we analysed 166 embryos in total, and 89.8\% (149/166) of them achieved a blastocyst stage. The mean total number of cells in embryos fixed after 5-day culture $(n=143)$ was $95.0+/-39.3$ and the percentage of cells with fragmented nuclei (i.e. probably apoptotic (Martelli et al. 2001, Vanden Berghe et al. 2013)) ranged from 0\% (in blastocysts) to $100 \%$ (in embryos arrested before the blastocyst stage), reaching a median of 3.6\%. Majority of the analysed embryos (76.2\%, 109/143) achieved at least 64-cell stage, when the first-embryonic cell lineages are already formed (Chazaud et al. 2006, Saiz et al. 2013). Those embryos had on average $82.4 \%$ TE cells (assessed by immunostaining of CDX2 protein, 


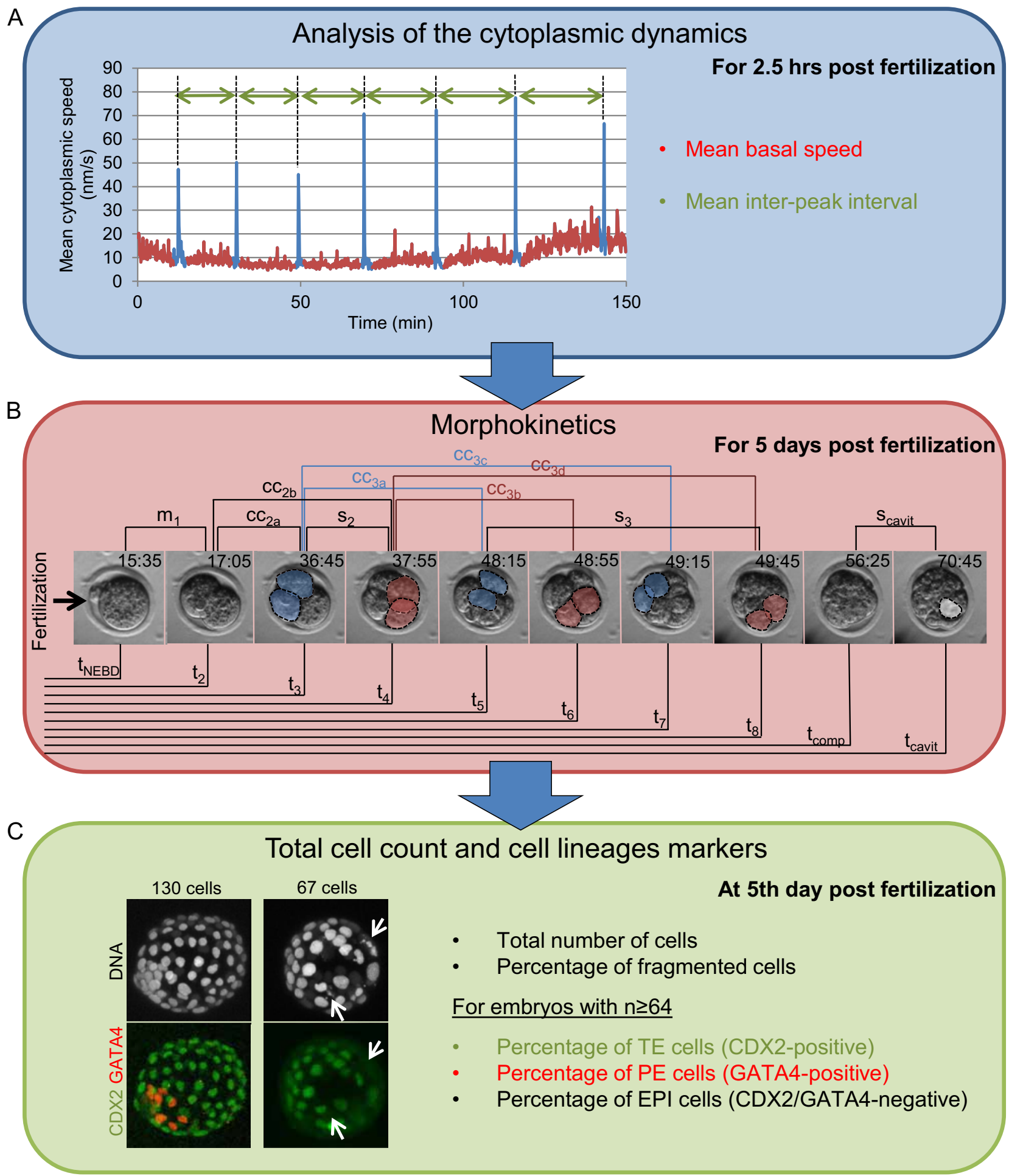

Figure 1 Schematic of the combined analysis of cytoplasmic and morphokinetic dynamics. (A) Fertilized mouse oocytes were first imaged every $10 \mathrm{~s}$ for $2.5 \mathrm{~h}$ to obtain data for the analysis of the cytoplasmic movement. A representative graph of the mean cytoplasmic speed in time is shown. Values averaged to calculate the mean basal speed are indicated in red, and those averaged to calculate the mean inter-peak interval are indicated in green. (B) Next, embryos were imaged every $10 \mathrm{~min}$ for 5 days to analyse dynamics of their cleavage divisions. Selected frames from a time-lapse movie of a representative embryo are shown. Blastomeres derived from one 2-cell stage blastomere are marked in blue, and from the other one are marked in red. (C) After 5 days, embryos were fixed and stained for CDX2 (TE marker, in green), GATA4 (PE marker, in red) and DNA (in white) in order to calculate the total number of cells, percentage of cells with fragmented nuclei and percentage of TE cells (CDX2-positive), PE cells (GATA4-positive) and EPI cells (CDX2- and GATA4-negative). Representative images of embryos expressing and not expressing GATA4 are shown. Arrows indicate fragmented nuclei. 
a transcription factor expressed specifically in TE cells (Strumpf et al. 2005)), 7.7\% PE cells (assessed by immunostaining of GATA4 protein, a transcription factor expressed specifically in PE cells (Cai et al. 2008)) and $6.0 \%$ presumed EPI cells (cells that did not express either CDX2 or GATA4).

\section{Cytoplasmic dynamics reflects embryo's ability to achieve a blastocyst stage and is associated with blastocyst quality}

First, we examined whether under our experimental conditions, cytoplasmic dynamics reflects developmental potential of mouse embryos, as it has been shown before (Ajduk et al. 2011). As expected, fertilization generated rhythmical changes in cytoplasmic speed in the oocytes that lasted until pronuclei were formed (Fig. 1A). The analysis of the cytoplasmic movements indicated that embryos, which failed to cavitate, had significantly lower mean cytoplasmic speed than those that formed blastocysts (median $9.12 \mathrm{vs} 12.19 \mathrm{~nm} / \mathrm{s}, P=0.006$ ) and tended to generate more frequent $\mathrm{Ca}^{2+}$ oscillations (median of the interval between subsequent $\mathrm{Ca}^{2+}$ transients: 14.44 vs $25.63 \mathrm{~min}, P=0.06$ ) (Table 1 ). In the latter case, the difference did not reach a statistically significant level probably due to a small number of embryos that arrested before the blastocyst stage. As both parameters were monotonic in the analysed range, we subjected them to a univariate logistic regression analysis, which indicated that $1 \mathrm{~nm} / \mathrm{s}$ rise in the mbs and $1 \mathrm{~min}$ rise in the mii increased chance for achieving a blastocyst stage by 30 and $15 \%$, respectively (Table 2 ).
We did not notice statistically significant correlations between the mbs or the mii and the total number of cells in the embryo (after 5-day culture), the percentage of cells with fragmented nuclei or the percentages of cells representing the first-embryonic cell linages (Supplementary Tables 1, 2 and 3 , see section on supplementary data given at the end of this article). However, the regression analysis revealed that these cytoplasmic parameters explain (in a linear or quadratic form, or combination of these two) a certain percentage of variability in the total number of embryo's cells or in the proportions of cells with fragmented nuclei and PE cells (Tables 3, 4 and 5). The total number of cells in the embryo was associated with a combination of linear and quadratic forms of the mii and 1 min rise in this parameter increased the total cell number by 8.41-0.15(2mii +1$)$ cells (Table 3$)$. It means that if the mii rises from 10 to $11 \mathrm{~min}$, then the total cell number in the embryo increases by $8.41-0.15(2 * 10+1)=5.26$ cells. However, if the mii rises from 20 to $21 \mathrm{~min}$, then the total cell number increases only by 2.26 cells, and if it rises from 40 to $41 \mathrm{~min}$, the total cell number decreases by 3.74 cells. Combination of linear and quadratic forms of the mii was also related to the percentage of abnormal cells with fragmented nuclei: 1 min rise in the mii decreased this percentage by $2.1-0.04(2 \mathrm{mii}+1)$ percentage points (Table 4). It means that if the mii rises from 10 to $11 \mathrm{~min}$, then the percentage of cells with fragmented nuclei in the embryo decreases by $2.1-0.04(2 * 10+1)=1.26$ percentage points. However, if the mii rises from 20 to $21 \mathrm{~min}$, then the percentage of such cells decreases only by 0.46 per cent points, and if it rises from 40 to $41 \mathrm{~min}$, the percentage increases by 1.14 percentage points.

Table 1 Values of cytoplasmic and morphokinetic parameters for embryos that achieved or did not achieve a blastocyst stage.

\begin{tabular}{|c|c|c|c|c|c|}
\hline \multirow[b]{2}{*}{ Parameters } & \multicolumn{2}{|c|}{ Blastocyst } & \multicolumn{2}{|c|}{$<$ Blastocyst } & \multirow[b]{2}{*}{$P$-value } \\
\hline & No. of embryos & Median $\left(\mathrm{Q}_{1} ; \mathrm{Q}_{3}\right)$ & No. of embryos & Median $\left(\mathrm{Q}_{1} ; \mathrm{Q}_{3}\right)$ & \\
\hline $\mathrm{mbs}$ & 122 & $12.19(9.90 ; 14.27)$ & 13 & $9.12(8.21 ; 11.08)$ & 0.006 \\
\hline $\mathrm{mii}$ & 109 & $25.63(21.18 ; 30.15)$ & 6 & $14.44(9.75 ; 26.15)$ & 0.06 \\
\hline$t_{\text {NEBD }}$ & 141 & $15.25(14.83 ; 15.92)$ & 18 & $14.75(14.33 ; 16.58)$ & NS* \\
\hline$t_{2}$ & 141 & $16.91(16.41 ; 17.58)$ & 17 & $16.67(16.33 ; 17.08)$ & NS \\
\hline $\mathrm{m}_{1}$ & 141 & $1.50(1.50 ; 1.67)$ & 17 & $2.00(1.83 ; 2.17)$ & $<0.001$ \\
\hline$t_{3}$ & 141 & $36.59(35.50 ; 37.84)$ & 16 & $38.83(36.83 ; 49.25)$ & 0.005 \\
\hline $\mathrm{CC}_{2 \mathrm{a}}$ & 141 & $19.67(18.67 ; 20.67)$ & 16 & $22.50(20.42 ; 30.75)$ & $<0.001$ \\
\hline$t_{4}^{2 d}$ & 141 & $37.67(36.41 ; 39.09)$ & 16 & $41.96(38.58 ; 50.83)$ & $<0.001$ \\
\hline $\mathrm{CC}_{2 \mathrm{~b}}$ & 141 & $20.67(20.00 ; 22.17)$ & 16 & $25.33(22.08 ; 34.08)$ & $<0.001$ \\
\hline $\mathrm{S}_{2}$ & 141 & $0.83(0.33 ; 1.33)$ & 16 & $2.08(0.42 ; 5.58)$ & 0.05 \\
\hline$t_{5}$ & 141 & $49.34(47.75 ; 52.25)$ & 13 & $54.83(50.67 ; 69.17)$ & $<0.001$ \\
\hline $\mathrm{CC}_{3 \mathrm{a}}$ & 141 & $12.50(11.67 ; 14.17)$ & 12 & $16.75(14.25 ; 18.83)$ & $<0.001$ \\
\hline$t_{6}$ & 140 & $49.92(48.17 ; 53.04)$ & 13 & $55.00(52.33 ; 71.92)$ & $<0.001$ \\
\hline $\mathrm{CC}_{3 \mathrm{~b}}$ & 140 & $13.00(11.83 ; 14.75)$ & 12 & $18.00(16.42 ; 21.58)$ & $<0.001$ \\
\hline$t_{7}$ & 139 & $50.83(48.75 ; 54.33)$ & 12 & $63.63(55.50 ; 75.00)$ & $<0.001$ \\
\hline $\mathrm{CC}_{3 \mathrm{c}}$ & 139 & $13.50(12.17 ; 15.50)$ & 11 & $22.00(17.83 ; 26.83)$ & $<0.001$ \\
\hline$t_{8}$ & 137 & $51.50(49.25 ; 56.25)$ & 9 & $62.75(61.17 ; 73.58)$ & $<0.001$ \\
\hline $\mathrm{CC}_{3 \mathrm{~d}}$ & 137 & $14.17(12.50 ; 16.67)$ & 9 & $25.00(21.67 ; 26.00)$ & $<0.001$ \\
\hline $\mathrm{s}_{3}$ & 137 & $2.17(1.33 ; 3.67)$ & 9 & $10.83(4.83 ; 12.00)$ & $<0.001$ \\
\hline$t_{\text {comp }}$ & 141 & $55.67(53.83 ; 58.67)$ & 15 & $70.00(62.58 ; 76.83)$ & $<0.001$ \\
\hline$t_{\text {cavit }}$ & 141 & $73.75(71.08 ; 77.92)$ & 5 & $101.67(95.33 ; 103.08)$ & $<0.001$ \\
\hline $\mathrm{s}_{\text {cavit }}$ & 141 & $18.33(15.83 ; 20.83)$ & 5 & $32.83(21.00 ; 35.50)$ & 0.009 \\
\hline
\end{tabular}

*NS - not significant. 
Table 2 Logistic regression analysis of cytoplasmic and morphokinetic parameters in relation to the embryo ability to achieve a blastocyst stage.

\begin{tabular}{|c|c|c|c|c|c|}
\hline \multirow{2}{*}{$\begin{array}{l}\text { Parameters } \\
\mathrm{mbs}\end{array}$} & \multirow{2}{*}{$\begin{array}{c}\begin{array}{c}\text { No. of } \\
\text { embryos }\end{array} \\
135\end{array}$} & \multirow{2}{*}{$\begin{array}{l}\begin{array}{l}\text { Odds } \\
\text { ratio }\end{array} \\
1.31\end{array}$} & \multicolumn{2}{|c|}{$\begin{array}{l}95 \% \text { confidence } \\
\text { interval }\end{array}$} & \multirow{2}{*}{$\begin{array}{c}\boldsymbol{P} \text {-value } \\
0.02\end{array}$} \\
\hline & & & 1.05 & 1.62 & \\
\hline mii & 115 & 1.15 & 1.02 & 1.30 & 0.02 \\
\hline $\mathrm{m}_{1}$ & 158 & 0.001 & 0.0001 & 0.02 & $<0.001$ \\
\hline$t_{3}$ & 157 & 0.81 & 0.73 & 0.91 & $<0.001$ \\
\hline $\mathrm{CC}_{2 \mathrm{a}}$ & 157 & 0.71 & 0.60 & 0.83 & $<0.001$ \\
\hline$t_{4}$ & 157 & 0.89 & 0.84 & 0.95 & 0.001 \\
\hline $\mathrm{CC}_{2 \mathrm{~b}}$ & 157 & 0.87 & 0.81 & 0.94 & 0.001 \\
\hline $\mathrm{s}_{2}$ & 157 & 0.89 & 0.82 & 0.97 & 0.008 \\
\hline$t_{5}$ & 154 & 0.82 & 0.75 & 0.90 & $<0.001$ \\
\hline $\mathrm{CC}_{3 \mathrm{a}}$ & 153 & 0.62 & 0.48 & 0.79 & $<0.001$ \\
\hline$t_{6}$ & 153 & 0.82 & 0.75 & 0.90 & $<0.001$ \\
\hline $\mathrm{CC}_{3 b}$ & 152 & 0.57 & 0.43 & 0.76 & $<0.001$ \\
\hline$t_{7}$ & 151 & 0.86 & 0.80 & 0.93 & $<0.001$ \\
\hline $\mathrm{CC}_{3 \mathrm{c}}$ & 150 & 0.67 & 0.55 & 0.81 & $<0.001$ \\
\hline $\mathrm{t}_{8}$ & 146 & 0.81 & 0.73 & 0.90 & $<0.001$ \\
\hline $\mathrm{CC}_{3 \mathrm{~d}}$ & 146 & 0.65 & 0.52 & 0.81 & $<0.001$ \\
\hline $\mathrm{s}_{3}$ & 146 & 0.72 & 0.61 & 0.85 & $<0.001$ \\
\hline$t_{\text {comp }}$ & 156 & 0.60 & 0.46 & 0.77 & $<0.001$ \\
\hline $\begin{array}{l}t_{\text {cavit }} \\
t_{\text {camp }}\end{array}$ & 146 & 0.83 & 0.75 & 0.92 & $<0.001$ \\
\hline $\mathrm{S}_{\text {cavit }}$ & 146 & 0.86 & 0.78 & 0.95 & 0.002 \\
\hline
\end{tabular}

The percentage of cells with fragmented nuclei was also associated with the mbs value: $1 \mathrm{~nm} / \mathrm{s}$ rise in the mbs decreases the percentage of these abnormal cells by 0.9 percentage points (Table 4 ). Moreover, the mbs in a quadratic form correlates with the percentage of $\mathrm{PE}$ cells (only embryos that achieved 64-cell stage, i.e. stage when all three first-embryonic cell linages are already present (Chazaud et al. 2006, Saiz et al. 2013), were analysed here): $1 \mathrm{~nm} / \mathrm{s}$ rise in the mbs increased the percentage of PE cells by $0.006(2 * \mathrm{mbs}+1)$ percentage points. It means that if the mbs rises from 7 to $8 \mathrm{~nm} / \mathrm{s}$, then the proportion of PE cells in the embryo increases by $0.006(2 * 7+1)=0.09$ percentage points; however, if the mbs rises from 14 to $15 \mathrm{~nm} / \mathrm{s}$, then the proportion increases almost twice as much, by 0.17 percentage points (Table 5). We did not observe any association between cytoplasmic parameters and a percentage of TE or EPI cells.

\section{Morphokinetic parameters are associated with embryo's ability to form a high-quality blastocyst}

Next, we assessed whether morphokinetic parameters are indicative of preimplantation developmental potential of mouse embryos, as it has been reported for human embryos (Wong et al. 2010, Cruz et al. 2012, Conaghan et al. 2013, VerMilyea et al. 2014, Milewski et al. 2015, Yang et al. 2015, Aparicio-Ruiz et al. 2016, Motato et al. 2016). According to our observations, embryos that did not cavitate divided and compacted at a significantly slower rate than those that reached the blastocyst stage (Table 1 ). This clearly indicated that in mouse, unlike in humans (Meseguer et al. 2011, Milewski et al. 2015, 2016a,b, Motato et al. 2016), morphokinetic parameters are monotonic and can be directly subjected to a logistic regression analysis. Depending on a parameter, $1 \mathrm{~h}$ prolongation decreased chances of the embryo to achieve a blastocyst stage by $10 \%$ (for $t_{4}$ ) to almost $100 \%$ (for $m_{1}$ ) (Table 2 ). Moreover, all examined morphokinetic parameters correlated with the total number of cells in the embryo (after 5-day culture) and the strongest association

Table 3 Linear regression analysis of cytoplasmic and morphokinetic parameters in relation to the total cell number in the embryo after 5-day culture.

\begin{tabular}{|c|c|c|c|c|c|}
\hline \multirow{2}{*}{$\frac{\text { Parameters }}{\mathrm{mii}+\mathrm{mii}^{2}}$} & \multirow{2}{*}{$\begin{array}{c}\text { No. of embryos } \\
103\end{array}$} & \multirow{2}{*}{$\frac{\text { Coefficient }}{8.41 /-0.15^{*}}$} & \multicolumn{2}{|c|}{$95 \%$ confidence interval } & \multirow{2}{*}{$\begin{array}{c}\boldsymbol{P} \text {-value } \\
<0.001 /<0.001^{*}\end{array}$} \\
\hline & & & $4.45 /-0.22 *$ & $12.37 /-0.07^{*}$ & \\
\hline$t_{\text {NEBD }}$ & 136 & -11.38 & -16.31 & -6.45 & $<0.001$ \\
\hline$t_{2}$ & 135 & -11.75 & -17.30 & -6.21 & $<0.001$ \\
\hline $\mathrm{m}_{1}$ & 135 & -54.90 & -90.89 & -18.91 & 0.003 \\
\hline$t_{3}$ & 135 & -5.57 & -6.83 & -4.32 & $<0.001$ \\
\hline $\mathrm{CC}_{2 \mathrm{a}}$ & 135 & -6.32 & -7.78 & -4.85 & $<0.001$ \\
\hline$t_{4}$ & 135 & -2.84 & -3.58 & -2.11 & $<0.001$ \\
\hline $\mathrm{s}_{2}$ & 135 & -3.32 & -4.74 & -1.90 & $<0.001$ \\
\hline $\mathrm{Cc}_{2 \mathrm{~b}}$ & 135 & -2.92 & -3.72 & -2.12 & $<0.001$ \\
\hline$t_{5}$ & 133 & -3.89 & -4.75 & -3.03 & $<0.001$ \\
\hline $\mathrm{CC}_{3 \mathrm{a}}$ & 132 & -6.50 & -8.50 & -4.49 & $<0.001$ \\
\hline$t_{6}$ & 132 & -3.58 & -4.38 & -2.77 & $<0.001$ \\
\hline $\mathrm{CC}_{3 \mathrm{~b}}$ & 131 & -5.90 & -7.66 & -4.14 & $<0.001$ \\
\hline$t_{7}$ & 130 & -2.73 & -3.40 & -2.07 & $<0.001$ \\
\hline $\mathrm{CC}_{3 \mathrm{c}}$ & 129 & -4.35 & -5.71 & -3.00 & $<0.001$ \\
\hline $\mathrm{t}_{8}$ & 126 & -2.94 & -3.78 & -2.10 & $<0.001$ \\
\hline $\mathrm{CC}_{3 \mathrm{~d}}$ & 126 & -3.83 & -5.31 & -2.35 & $<0.001$ \\
\hline $\mathrm{s}_{3}$ & 126 & -3.42 & -5.45 & -1.40 & 0.001 \\
\hline $\mathrm{t}_{\text {comp }}$ & 133 & -4.29 & -5.42 & -3.16 & $<0.001$ \\
\hline$t_{\text {cavit }}$ & 129 & -2.33 & -2.90 & -1.75 & $<0.001$ \\
\hline $\mathrm{S}_{\text {cavit }}$ & 129 & -2.59 & -3.48 & -1.70 & $<0.001$ \\
\hline
\end{tabular}

*For mii and mii $^{2}$ respectively. 
Table 4 Linear regression analysis of morphokinetic parameters in relation to the percentage of cells with fragmented nuclei in the embryo after 5-day culture.

\begin{tabular}{|c|c|c|c|c|c|}
\hline \multirow{2}{*}{$\begin{array}{l}\text { Parameter } \\
\mathrm{mbs}\end{array}$} & \multirow{2}{*}{$\begin{array}{c}\text { No. of embryos* } \\
119\end{array}$} & \multirow{2}{*}{$\begin{array}{c}\text { Coefficient } \\
-0.93\end{array}$} & \multicolumn{2}{|c|}{$95 \%$ confidence interval } & \multirow{2}{*}{$\begin{array}{l}\boldsymbol{P} \text {-value } \\
0.03\end{array}$} \\
\hline & & & -1.76 & -0.10 & \\
\hline $\mathrm{mii}+\mathrm{mii}^{2}$ & 103 & $-2.13 / 0.04^{*}$ & $-3.81 / 0.00^{*}$ & $-0.45 / 0.07^{*}$ & $0.01 / 0.03 *$ \\
\hline$t_{\text {NEBD }}$ & 135 & 5.76 & 3.66 & 7.86 & $<0.001$ \\
\hline$t_{2}$ & 134 & 3.67 & 1.41 & 5.92 & 0.002 \\
\hline$t_{3}$ & 134 & 2.51 & 2.05 & 2.97 & $<0.001$ \\
\hline $\mathrm{CC}_{2 \mathrm{a}}$ & 134 & 3.04 & 2.52 & 3.55 & $<0.001$ \\
\hline$t_{4}$ & 134 & 1.39 & 1.14 & 1.65 & $<0.001$ \\
\hline $\mathrm{CC}_{2 \mathrm{~b}}$ & 134 & 1.50 & 1.23 & 1.77 & $<0.001$ \\
\hline $\mathrm{s}_{2}$ & 134 & 1.87 & 1.36 & 2.39 & $<0.001$ \\
\hline$t_{5}$ & 132 & 0.98 & 0.73 & 1.23 & $<0.001$ \\
\hline $\mathrm{CC}_{3 \mathrm{a}}$ & 131 & 1.22 & 0.62 & 1.81 & $<0.001$ \\
\hline$t_{6}$ & 131 & 0.92 & 0.68 & 1.15 & $<0.001$ \\
\hline $\mathrm{CC}_{3 \mathrm{~b}}$ & 130 & 1.19 & 0.67 & 1.71 & $<0.001$ \\
\hline$t_{7}$ & 129 & 0.46 & 0.30 & 0.62 & $<0.001$ \\
\hline $\mathrm{CC}_{3 \mathrm{c}}$ & 128 & 0.55 & 0.22 & 0.88 & 0.001 \\
\hline$t_{8}$ & 126 & 0.45 & 0.26 & 0.65 & $<0.001$ \\
\hline $\mathrm{CC}_{3 \mathrm{~d}}$ & 126 & 0.47 & 0.14 & 0.81 & 0.006 \\
\hline$t_{\text {comp }}$ & 133 & 1.07 & 0.63 & 1.50 & $<0.001$ \\
\hline$t_{\text {cavit }}$ & 129 & 0.27 & 0.14 & 0.39 & $<0.001$ \\
\hline $\mathrm{S}_{\text {cavit }}$ & 129 & 0.31 & 0.13 & 0.50 & 0.001 \\
\hline
\end{tabular}

*For mii and $\mathrm{mii}^{2}$ respectively.

$(R<-0.5)$ was observed for timings from $t_{3}$ to $t_{8}$, and for $t_{\text {comp }}$ (Supplementary Table 1). Again, depending on the parameter, the univariate linear regression analysis showed that $1 \mathrm{~h}$ prolongation decreased the total cell number to a different extent: from approximately 2 cells (for $t_{\text {cavit }}$ ) to almost 55 cells (for $m_{1}$ ) (Table 3 ).

Numerous morphokinetic parameters correlated with the percentage of cells with fragmented nuclei in the embryo (Supplementary Table 2). In general, the slower the divisions, the higher the degree of nuclear fragmentation observed. The strongest association was found for timings $t_{3}-t_{5} \quad(R>0.35)$. According to a univariate linear analysis, $1 \mathrm{~h}$ prolongation in division timings increased the percentage of cells with fragmented nuclei by 0.3 (for $t_{\text {cavit }}$ and $s_{\text {cavit }}$ ) to 5.7 (for $t_{\text {NEBD }}$ ) percentage points (Table 4).

Interestingly, several morphokinetic parameters related to the first three rounds of cleavage divisions (up to $t_{6}$ ) correlated with the embryo's ability to form $\mathrm{PE}$, although the association was weaker than for the embryo's total cell number or the percentage of cells with fragmented nuclei (Supplementary Table 3). The strongest association $(R<-0.25)$ was observed for $\mathrm{t}_{\mathrm{NEBD}}, \mathrm{t}_{2}$ and

Table 5 Linear regression analysis of morphokinetic parameters in relation to the percentage of primitive endoderm cells in the $\geq 64$-cell embryo after 5-day culture.

\begin{tabular}{lcccrl}
\hline Parameter & $\begin{array}{c}\text { No. of } \\
\text { embryos }\end{array}$ & Coefficient & \multicolumn{2}{c}{$\begin{array}{c}\text { 95\% confidence } \\
\text { interval }\end{array}$} & P-value \\
\hline $\mathrm{mbs}^{2}$ & 91 & 0.006 & 0.00 & 0.01 & 0.049 \\
$\mathrm{t}_{\text {NEBD }}$ & 105 & -0.94 & -1.81 & -0.08 & 0.03 \\
$\mathrm{t}_{2}$ & 105 & -0.96 & -1.79 & -0.13 & 0.02 \\
$\mathrm{t}_{3}$ & 105 & -0.54 & -0.96 & -0.12 & 0.01 \\
$\mathrm{t}_{5}$ & 105 & -0.27 & -0.50 & -0.03 & 0.03 \\
\hline
\end{tabular}

again for $t_{3}$ and $t_{5}$. According to the univariate linear regression analysis performed on embryos that achieved 64-cell stage, $1 \mathrm{~h}$ prolongation of these morphokinetic parameters decreased the percentage of PE cells by 0.3 (for $t_{5}$ ) to 1.0 (for $t_{2}$ ) percentage points (Table 5). We did not observe correlation between any of the morphokinetic parameters analysed and the percentage of TE or EPI cells (Supplementary Table 3).

\section{Limited interdependence between cytoplasmic and morphokinetic parameters}

Next, we wished to examine whether cytoplasmic dynamics analysed shortly after fertilization corresponds to the dynamics of subsequent cleavage divisions. Interestingly, both the mbs and the mii correlated with the length of cell cycle in 2-cell stage blastomeres $\left(\mathrm{CC}_{2 a}\right.$ and $\mathrm{Cc}_{2 \mathrm{~b}}$; Table 6). Additionally, the mii correlated with the length of cell cycle in 4-cell stage blastomeres and with division times from $t_{5}$ to $t_{8}$. The strongest association $(R<-0.25)$ was observed between the mbs and $\mathrm{cc}_{2 \mathrm{a}}$ and the mii and $\mathrm{CC}_{2 \mathrm{a}}$ and $\mathrm{t}_{6}$ (Table 6).

\section{Combined analysis of cytoplasmic and morphokinetic parameters helps to assess the total number of cells in the embryo}

Since only a limited number of cytoplasmic and morphokinetic parameters were interdependent, we were able to combine these two sets of parameters and create a statistical model assessing embryo's developmental potential, defined as the total number of cells after 5-day culture. Our model, based on a multivariate linear regression analysis, included 
Table 6 Correlation between parameters describing cytoplasmic dynamics and morphokinetic parameters.

\begin{tabular}{lccccccc}
\hline & \multicolumn{3}{c}{ Mean basal speed } & & \multicolumn{3}{c}{ Mean inter-peak interval } \\
\cline { 2 - 4 } \cline { 6 - 8 } Parameter* & $\begin{array}{c}\text { No. of } \\
\text { embryos }\end{array}$ & $R$ & $P$-value & & $\begin{array}{c}\text { No. of } \\
\text { embryos }\end{array}$ & $R$ & $P$-value \\
\hline $\mathrm{CC}_{2 \mathrm{a}}$ & 129 & -0.26 & 0.003 & & 109 & -0.29 & 0.002 \\
$\mathrm{CC}_{2 \mathrm{~b}}$ & 129 & -0.23 & 0.009 & & 109 & & $\mathrm{NS} * *$ \\
$\mathrm{t}_{5}$ & 126 & & $\mathrm{NS}$ & & 108 & -0.21 & 0.03 \\
$\mathrm{CC}_{3 \mathrm{a}}$ & 125 & & $\mathrm{NS}$ & & 107 & -0.20 & 0.04 \\
$\mathrm{t}_{6}$ & 125 & & $\mathrm{NS}$ & & 107 & -0.26 & 0.007 \\
$\mathrm{CC}_{3 \mathrm{~b}}$ & 124 & & $\mathrm{NS}$ & & 106 & -0.20 & 0.04 \\
$\mathrm{t}_{7}$ & 124 & & $\mathrm{NS}$ & & 106 & -0.22 & 0.03 \\
$\mathrm{t}_{8}$ & 119 & & $\mathrm{NS}$ & & 103 & -0.23 & 0.02 \\
$\mathrm{~s}_{\text {cavit }}$ & 121 & -0.20 & 0.03 & & 104 & & $\mathrm{NS}$ \\
\hline
\end{tabular}

*Morphokinetic parameters that do not correlate with any of the cytoplasmic parameters $(P>0.05)$ were not shown. ${ }^{* *} \mathrm{NS}-$ not significant.

3 parameters: (i) the mii (linear and quadratic), (ii) $\mathrm{t}_{4}$ and (iii) $\mathrm{t}_{\text {comp, }}$, and explained $45 \%$ of variability in the total number of embryonic cells $\left(R^{2}=0.451\right)$, i.e. more than any of the parameters separately (Fig. 2 and Table 7). According to our model, $1 \mathrm{~h}$ prolongation of $\mathrm{t}_{4}$ or $t_{\text {comp }}$ (when values of the other two parameters were unchanged) decreased the estimated total number of embryonic cells by 1.70 and 1.84 cells, respectively. On the other hand, $1 \mathrm{~min}$ rise in the mii increased the total cell number by $5.39-0.09(2 \mathrm{mii}+1)$ cells. It means that if the mii rises from 10 to $11 \mathrm{~min}$, then the total cell number in the embryo (assuming that values of other two parameters remain unchanged) increases by $5.39-0.09(2 * 10+1)=3.5$ cells. However, if the mii rises from 20 to $21 \mathrm{~min}$, then the total cell number increases only by 1.7 cells, and if it rises from 40 to $41 \mathrm{~min}$, the total cell number decreases by 1.9 cells. Therefore, our model comprises two long-standing observations: firstly, slower divisions and delayed compaction indicate lower developmental potential of the embryo; secondly, there is a certain range of the speed-peak frequency (i.e. the frequency of $\mathrm{Ca}^{2+}$ oscillations) optimal for the embryonic development: both too frequent and too rare $\mathrm{Ca}^{2+}$ transients are detrimental for the embryo.

\section{Combined imaging of cytoplasmic dynamics and morphokinetics is safe for the preimplantation development of mouse embryos}

In order to investigate whether imaging required for the combined analysis of cytoplasmic and morphokinetic parameters affects preimplantation development of mouse embryos, we examined their ability to cavitate and form the first three embryonic cell lineages. We found that $93.7 \%(60 / 64)$ of embryos that were initially imaged every $10 \mathrm{~s}$ for $2.5 \mathrm{~h}$ (imaging for the cytoplasmic analysis) and then every $10 \mathrm{~min}$ for the next 5 days (imaging for the morphokinetic analysis) cavitated before the end of the in vitro culture. Similar rate of cavitation was observed for the control embryos

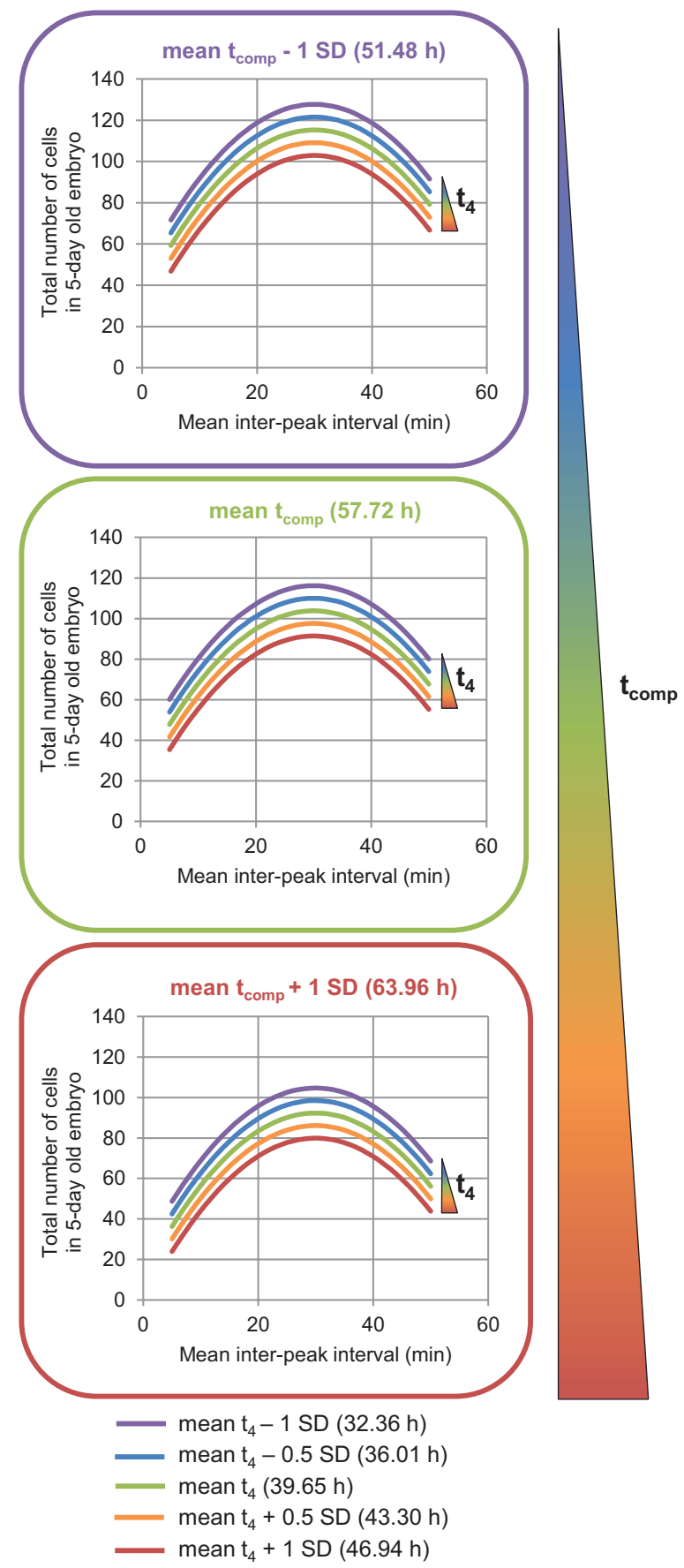

Figure 2 Regression model linking cytoplasmic and morphokinetic parameters with the total number of cells in a 5-day-old mouse embryo. Graphs show association between the model parameters: the mean inter-peak interval (linear and quadratic), $\mathrm{t}_{4}$ and $\mathrm{t}_{\text {comp, }}$ and the total number of cells in 5-day-old mouse embryo. The mean inter-peak interval (mii) values are presented on $X$ axes and the total cell number are presented on $Y$ axes. $t_{4}$ is encoded in the curve colours and only five selected values are presented: the mean value of $t_{4}$, the mean value $+/-0.5$ S.D. and the mean value $+/-1$ S.D. $t_{\text {comp }}$ is encoded in the colour of the graph edgings. Only three $t_{\text {comp }}$ values are presented: the mean value of $t_{\text {comp }}$ and the mean value $+/-1$ S.D. The curves are described by the following mathematical formula: total number of cells $=196.66+5.39 * \mathrm{mii}-0.09 * \mathrm{mii}^{2}-1.7 * \mathrm{t}_{4}-1.84 * \mathrm{t}_{\text {comp }}$. 
Table 7 Multivariate linear regression model based on selected parameters assessing total number of cells in the embryo after 5-day culture.

\begin{tabular}{lccrc}
\hline Parameter & Coefficient & \multicolumn{2}{c}{ 95\% confidence interval } & $\boldsymbol{P}$-value \\
\hline $\mathrm{mii}$ & 5.39 & 1.93 & 8.85 & 0.003 \\
$\mathrm{mii}^{2}$ & -0.09 & -0.16 & -0.02 & 0.008 \\
$\mathrm{t}_{4}$ & -1.70 & -2.58 & -0.82 & $<0.001$ \\
$\mathrm{t}_{\text {comp }}$ & -1.84 & -3.52 & -0.16 & 0.03 \\
\hline
\end{tabular}

No. of embryos $=97, R^{2}=0.451$. subjected either only to the cytoplasmic imaging, or to the morphokinetic imaging, or to standard in vitro culture without any imaging (84.8\% (67/79), 84.4\% (54/64), 94.5\% (69/73) respectively, $P>0.05)$ (Fig. 3A). The average number of cells in embryos subjected to the combined imaging was similar to values achieved in the other three groups of embryos (medians of 125.0, 98.0, 97.5 and 133.5 , respectively, $P>0.05$ ), the same as the average percentage of cells with fragmented nuclei,
A

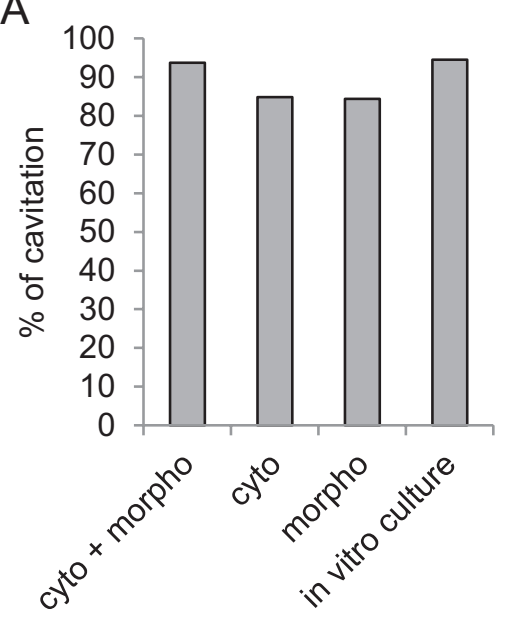

D

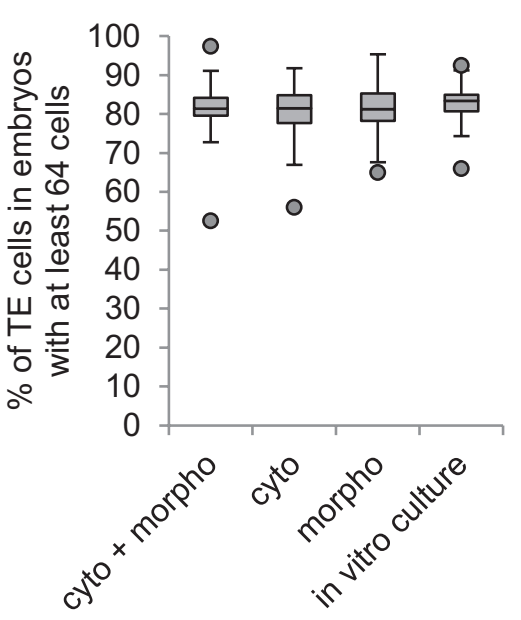

B

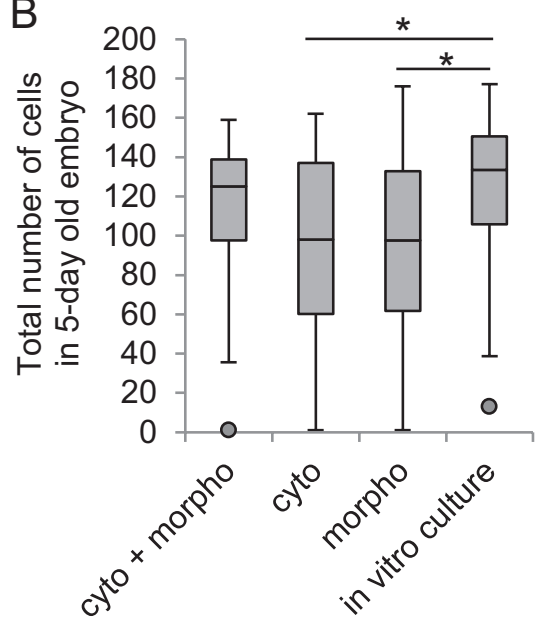

E

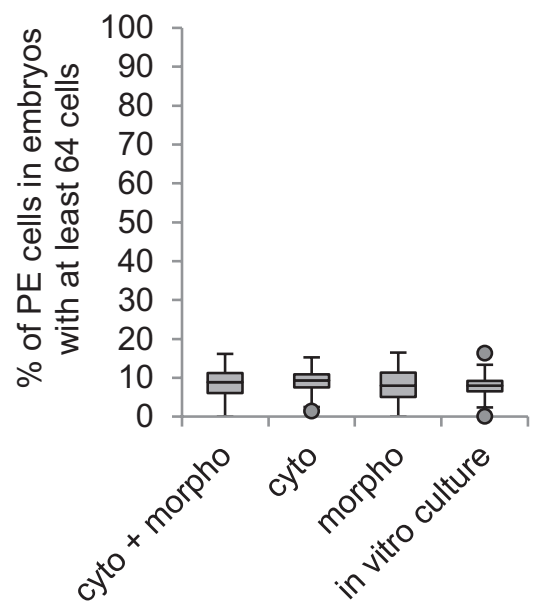

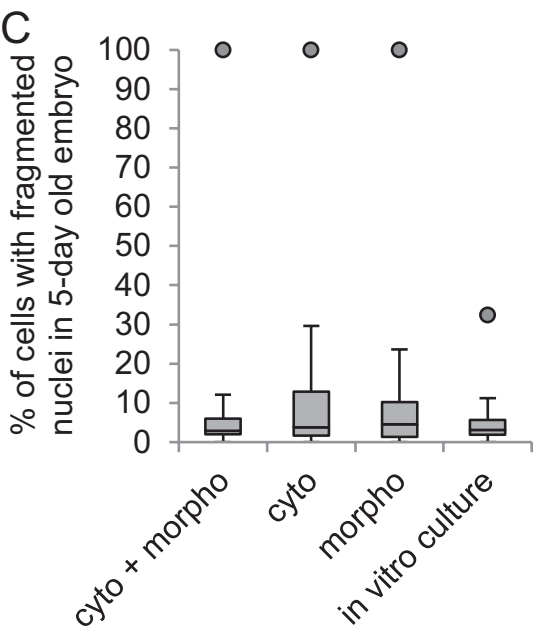

$\mathrm{F}$

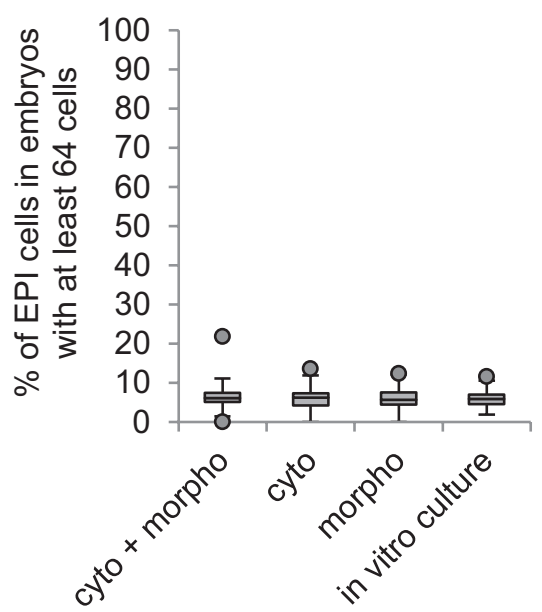

Figure 3 Impact of the combined imaging required for the analysis of cytoplasmic and morphokinetic parameters on preimplantation development of mouse embryos. (A) Rate of blastocyst formation for 5-day-old embryos subjected to the combined imaging required for cytoplasmic and morphokinetic analyses (cyto + morpho, $n=64)$, only cytoplasmic imaging (cyto, $n=79$ ), only morphokinetic imaging (morpho, $n=64$ ) or only standard in vitro culture without imaging (in vitro culture, $n=73$ ). (B) Total number of cells and (C) percentage of cells with fragmented nuclei in 5-day-old embryos subjected to the combined imaging required for cytoplasmic and morphokinetic analyses (cyto + morpho, $n=62$ ), only cytoplasmic imaging (cyto, $n=76$ ), only morphokinetic imaging (morpho, $n=62$ ) or only standard in vitro culture without imaging (in vitro culture, $n=68$ ). (D) Percentage of TE cells, (E) PE cells and (F) EPI cells in 5-day-old embryos with at least 64 cells, subjected to the combined imaging required for cytoplasmic and morphokinetic analyses (cyto + morpho, $n=57$ ), only cytoplasmic imaging (cyto, $n=56$ ), only morphokinetic imaging (morpho, $n=46$ ) or only standard in vitro culture without imaging (in vitro culture, $n=61$ ). Graphs $(B, C, D, E$ and $F)$ present median and the first and the third quartile values. The ends of the whisker are set at $1.5 *$ IQR above the third quartile and $1.5 * \mathrm{IQR}$ below the first quartile. Dots show the minimum and maximum values if they are outside the range (outliers). ${ }^{*} P<0.001$. 
i.e., potentially apoptotic cells (medians of 2.9, 3.7, 4.5 and $3.1 \%$, respectively, $P>0.05$ ) (Fig. $3 \mathrm{~B}$ and $\mathrm{C}$ ). However, we noticed that embryos subjected exclusively to the cytoplasmic imaging or the morphokinetic imaging had slightly less cells that embryos just cultured in vitro $(P<0.01)$. It is difficult to explain this discrepancy, and we surmise that it may be related to a natural variability between individual embryos, especially that, due to equipment limitations, the under-achieving groups were obtained and filmed separately from the control, non-imaged embryos and embryos subjected to the combined imaging. We also cannot exclude a possibility that manipulations and illumination related to filming may have after all some impact on the rate of cell division, especially when a cohort of embryos occurs to be more susceptible to suboptimal external conditions. Additionally, we calculated the average percentages of TE, PE and EPI cells in embryos that had at least 64 cells after 5-day culture: they were also the same for all four types of embryos (TE: medians of 81.4, $81.5,81.2,83.3 \%$, respectively, $P>0.05 ;$ PE: medians of 8.8, 9.3, 8.0, 8.0\%, $P>0.05$; EPI: medians of 6.1, 6.1, $5.7,5.8 \%$, respectively, $P>0.05$ ) (Fig. 3D, E and F). In summary, combined imaging required for the analysis of both cytoplasmic and morphokinetic parameters does not alter the preimplantation development of mouse embryos.

\section{Discussion}

In the present paper, we showed that both cytoplasmic and morphokinetic parameters can serve as biomarkers of embryo's ability to form a good-quality blastocyst, and that they are associated with the total number of cells in 5-day-old embryos. Moreover, we showed that embryos subjected to the combined imaging, required for the analysis of cytoplasmic and morphokinetic parameters, display the same quality of preimplantation development as embryos filmed exclusively for the cytoplasmic or the morphokinetic analysis, and, most importantly, as embryos that were cultured in vitro without any kind of imaging. Although embryos subjected to single-type imaging had, quite unexpectedly, less cells at the end of the in vitro culture than embryos that were cultured in vitro without imaging, in all four groups embryos formed the first-embryonic cell lineages with the same proportional efficiency. It has been shown that one of the key requirements for a full-term development is a sufficient number of EPI cells at the time of implantation (estimated for mice as at least four; Morris et al. 2012) and this number was on average reached by embryos subjected to both combined and single-type imaging, as well as by non-imaged embryos. Although we cannot exclude a possibility that filming affects the rate of cell divisions in embryos and in consequence decreases their developmental capacity at later stages, the fact that it did not prevent them from reaching the
EPI threshold suggests that they were likely to maintain a sufficient developmental potential to undergo a successful postimplantation development. Indeed, numerous publications prove that mammalian embryos subjected only to one type of imaging, cytoplasmic or morphokinetic, or simply only to the in vitro culture can successfully implant and give rise to healthy newborns (Nakahara et al. 2010, Pribenszky et al. 2010, Ajduk et al. 2011, Cruz et al. 2011, Kirkegaard et al. 2012, Weinerman et al. 2016). Since data presented here indicate that embryos subjected to the combined imaging develop during preimplantation stages at least as well as other types of analysed embryos, it is plausible that the combined imaging also does not inhibit the postimplantation development of embryos. It is important to mention, however, that in our experiments, we used F1 hybrid mice, which produce oocytes and embryos relatively resistant to adverse effects of experimental manipulations and in vitro conditions. We achieved very high percentage of cavitation, significantly higher than values reported usually for human or cattle embryos (Tamassia et al. 2003, Cruz et al. 2011, Catteeuw et al. 2017, Sfontouris et al. 2017). Thus, further research is required first to verify the safety of our imaging method for more sensitive objects, and second, to investigate how our observations refer to embryos with lower developmental rates.

The fact that the cytoplasmic and morphokinetic parameters correlate with the embryo's ability to form a good-quality blastocyst does not mean that they directly contribute to the embryo's ability to cavitate or to form the first-cell linages; they just reflect other cellular properties that are crucial for developmental potential of the embryo. Therefore, to understand what statistical analysis of the mbs, the mii and the cleavage timings tells us about embryo quality, we need to identify cellular properties affecting cytoplasmic or morphokinetic dynamics.

Analysis of the cytoplasmic movements provides data related to quality of the oocyte: its cytoskeleton and its machinery involved in the generation of sperminduced $\mathrm{Ca}^{2+}$ oscillations. Low mean cytoplasmic basal speed reflects hindered dynamics of the actomyosin cytoskeleton: both depolymerization and overstabilization of actin filaments, the same as inhibition of myosin, resulted in significantly decreased mbs (Ajduk et al. 2011). Disturbed functionality of the actomyosin cytoskeleton leads to altered organelle trafficking and/or problems with executing cytokinesis in cells (Sun \& Schatten 2006, D'Avino et al. 2015), and, in consequence, decreases developmental potential of embryos. Indeed, we noticed that zygotes displaying slow movement of the cytoplasm were less likely to develop to the blastocyst stage, had more abnormal cells with fragmented nuclei and less PE cells. Analysis of cytoplasmic speed could be especially useful in the case of cryo-preserved oocytes, as both slow freezing 
and vitrification tend to disrupt actin cytoskeleton of the cell (Saunders et al. 1999, Hosu et al. 2008, Luciano et al. 2009).

Since the fast directional cytoplasmic movements are triggered by $\mathrm{Ca}^{2+}$ elevations (Ajduk et al. 2011), the second cytoplasmic parameter, the mii, reflects the mean interval between subsequent $\mathrm{Ca}^{2+}$ transients and thus describes frequency of $\mathrm{Ca}^{2+}$ oscillations. $\mathrm{Ca}^{2+}$ oscillations trigger numerous processes essential for the proper embryonic development, such as completion of meiosis in the oocyte, formation of the zona-dependent block to polyspermy or initiation of cleavage divisions. Moreover, they have been shown to regulate activity of mitochondria, recruitment of maternal mRNAs and expression of embryonic genome (Dumollard et al. 2004, Ozil et al. 2005, 2006, Campbell \& Swann 2006, Ducibella et al. 2006, Toth et al. 2006). All the abovementioned processes require that $\mathrm{Ca}^{2+}$ concentration in the cytoplasm is elevated for a certain time, and the total duration of this elevation depends, among others, on the frequency of $\mathrm{Ca}^{2+}$ transients (Ozil et al. 2005, 2006, Ducibella et al. 2006). Importantly, it has been shown that both overly limited and overly prolonged $\mathrm{Ca}^{2+}$ elevation changes the expression pattern of genes involved in the embryonic development and impairs perimplantation or postimplantation development of the embryo (Ozil et al. 2006, Toth et al. 2006). We found that embryos displaying too frequent $\mathrm{Ca}^{2+}$ oscillations (low mii) tended to arrest even before the blastocyst stage. Interestingly, we also noticed that although an initial rise in the mii was beneficial for the embryo (it led to an increase in the total number of embryo's cells after 5-day culture and to a decrease in the percentage of cells with fragmented nuclei), a further increase in the mii value depressed the embryo's quality (it decreased the total number of cells and increased the percentage of cells with fragmented nuclei).

Division timings that are the main target of morphokinetic analysis also reflect a wide range of embryo's properties, both cytoplasmic and nuclear (reviewed in Ajduk \& Zernicka-Goetz (2013) and Milewski \& Ajduk (2017)). Timely divisions may indicate that activation events accompanying fertilization, such as $\mathrm{Ca}^{2+}$ oscillations, occurred correctly, cytoskeleton is functional and mitochondria provide sufficient amounts of energy required for DNA synthesis and chromosome segregation. It has also been suggested that timely divisions correspond to a high-quality nuclear apparatus. Delayed divisions may be a sign of DNA damage or chromosomal aberrations that activated one of the cell cycle checkpoints and halted the cell cycle progression. Interestingly, recent results obtained for mouse embryos have shown that missegregation of chromosomes does not strongly affect length of the cell cycle, at least at 8- to 128-cell stage (Bolton et al. 2016, Vazquez-Diez et al. 2016). On the contrary, in human 1- to 8-cell stage embryos, aneuploidy seems to affect at least some division timings (Chavez et al. 2012, Vera-Rodriguez et al. 2015), indicating that there may be species- and/ or stage-related differences in the blastomere reaction to ploidy defects. Our results show that division timings of the $2 \mathrm{nd}$ and $3 \mathrm{rd}$ rounds of cleavage are the most potent indicators of embryonic developmental potential. They are indeed frequently used in algorithms assessing quality of human and animal embryos (Wong et al. 2010, Cruz et al. 2012, Conaghan et al. 2013, VerMilyea et al. 2014, Cetinkaya et al. 2015, Milewski et al. 2015, Motato et al. 2016, Weinerman et al. 2016, Milewski \& Ajduk 2017). This seems logical, because irregularities present in early embryonic stages are inherited by more descendant blastomeres and compromise viability of the embryo more heavily. For the same reason, as we showed in the present paper, delay in the early cleavage events (e.g. zygotic NEBD or first embryonic divisions) affects the percentage of abnormal (probably apoptotic) cells with fragmented nuclei in the embryo more than a delay at the later developmental stages.

Interestingly, our analysis indicates that there is one important difference between mouse and human morphokinetics. In mice, morphokinetic parameters tend to be monotonic, i.e., unidirectional change in their value (e.g. an increase) leads to a unidirectional change in the output. In contrast, in humans many morphokinetic parameters are non-monotonic, e.g., cleavage divisions that are both too slow and too fast correlate with the poor embryo quality, so a prolongation of the cleavage timings first increases the embryo quality, then, beyond a certain value, decreases it (Meseguer et al. 2011, Milewski et al. 2015, 2016a,b, Motato et al. 2016, Milewski \& Ajduk 2017). This discrepancy is probably caused by the fact that, unlike human embryos, mouse embryos usually do not undergo the so-called direct cleavages (i.e. divisions to 3 or more daughter cells within less than $5 \mathrm{~h}$ that are detrimental for the embryo quality (Campbell \& Fishel 2015)) and therefore they do not divide 'too fast'.

Our results also indicate that there is a limited interdependence between cytoplasmic dynamics in freshly fertilized oocytes and dynamics of cleavage divisions. We observed that the mbs is associated only with early cleavage timings, namely with length of the cell cycle in 2-cell stage blastomeres. As robust activation of the embryonic genome in mice starts at the 2-cell stage (Flach et al. 1982, reviewed in Li et al. (2013) and Biechele et al. (2015)), quality of the cytoskeleton inherited from the oocyte and reflected by the mbs is no longer crucial for the divisions at later developmental stages. On the other hand, the mii is associated with a much wider range of morphokinetic parameters, including timings of both early and late cleavage events. This also accords with our knowledge about biology of mammalian embryos: as mentioned before, the pattern of $\mathrm{Ca}^{2+}$ oscillations impacts many aspects of embryonic development, including those associated with later developmental events (Ozil et al. 2005, 2006, Ducibella et al. 2006, Toth et al. 2006). 
Finally, we showed that a combined analysis of cytoplasmic dynamics and morphokinetics can help to assess the total number of embryo's cells after 5-day culture. We set the total number of cells as our indicator of embryo's viability because it reflects directly the quality of the embryonic cell cycles resulting from the quality of the nuclear apparatus, energy metabolism, cytoskeleton, etc. Our model is based on 3 parameters:

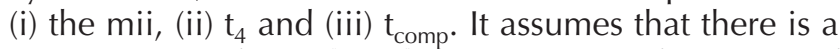
certain range of speed-peak frequency (i.e. frequency of $\mathrm{Ca}^{2+}$ oscillations) optimal for the embryonic development (Ozil et al. 2005, 2006, Ducibella et al. 2006, Toth et al. 2006). It also reflects the fact that a delayed division to the 4-cell stage (high $t_{4}$ value) and delayed compaction (high $t_{\text {comp }}$ value) mirror most likely the condition of the nuclear apparatus and the cytoplasmic component of the embryo. Timing of compaction is a particularly interesting parameter as compaction involves reorganization of the cellular cytoskeleton and formation of new intercellular connections between blastomeres but does not depend directly on the cell cycle progression (Kojima et al. 2014). As cellular cytoskeleton is often damaged during freezing and thawing procedures (Saunders et al. 1999, Hosu et al. 2008, Luciano et al. 2009, Dalcin et al. 2013, Hendriks et al. 2015, Kulíková et al. 2016), timing of compaction could be especially useful for selection of embryos obtained from cryo-preserved oocytes (or simply for selection of cryo-preserved embryos, although in such cases, another algorithm that does not require imaging immediately after fertilization would have to be used). It is however important to note that our model has only a correlative character and, before it can be used clinically, it needs to be redeveloped as a predictive model and undergo a successful validation.

In summary, analyses of cytoplasmic dynamics and morphokinetics provide a great amount of information about the embryo's wellbeing. Many of the parameters obtained by time-lapse imaging correspond to embryo quality markers such as the ability to cavitate, the total number of cells, the percentages of cells with fragmented nuclei and percentage of PE cells reached at the end of preimplantation development. Most importantly, however, we show that models that combine cytoplasmic and morphokinetic parameters and reflect diverse cellular properties of the embryo may help to improve existing protocols of the embryo quality assessment.

\section{Supplementary data}

This is linked to the online version of the paper at https://doi.org/10.1530/REP-17-0230.

\section{Declaration of interest}

$\mathrm{A} A$ is a co-inventor in the patent 'Methods for predicting mammalian embryo viability' (patent no. US 9410939 B2).

\section{Funding}

The study was founded by the SONATA grant (UMO2012/07/D/NZ5/04301) from the National Science Centre (Poland) to A A.

\section{Acknowledgements}

The authors would like to thank Prof. Marek Maleszewski for a critical reading of the manuscript.

\section{References}

Ahlstrom A, Park H, Bergh C, Selleskog U \& Lundin K 2016 Conventional morphology performs better than morphokinetics for prediction of live birth after day 2 transfer. Reproductive Biomedicine Online 33 61-70. (https://doi.org/10.1016/j.rbmo.2016.03.008)

Ajduk A \& Zernicka-Goetz M 2013 Quality control of embryo development. Molecular Aspects of Medicine 34 903-918. (https://doi.org/10.1016/j. mam.2013.03.001)

Ajduk A, Ilozue T, Windsor S, Yu Y, Seres KB, Bomphrey RJ, Tom BD, Swann K, Thomas A, Graham C et al. 2011 Rhythmic actomyosindriven contractions induced by sperm entry predict mammalian embryo viability. Nature Communications 2 417. (https://doi.org/10.1038/ ncomms1424)

Aparicio B, Cruz M \& Meseguer M 2013 Is morphokinetic analysis the answer? Reproductive Biomedicine Online 27 654-663. (https://doi. org/10.1016/j.rbmo.2013.07.017)

Aparicio-Ruiz B, Basile N, Perez Albale S, Bronet F, Remohi J \& Meseguer M 2016 Automatic time-lapse instrument is superior to singlepoint morphology observation for selecting viable embryos: retrospective study in oocyte donation. Fertility and Sterility 106 1379.e10-1385.e10. (https://doi.org/10.1016/j.fertnstert.2016.07.1117)

Armstrong S, Vail A, Mastenbroek S, Jordan V \& Farquhar C 2015 Timelapse in the IVF-lab: how should we assess potential benefit? Human Reproduction 30 3-8. (https://doi.org/10.1093/humrep/deu250)

Biechele S, Lin CJ, Rinaudo PF \& Ramalho-Santos M 2015 Unwind and transcribe: chromatin reprogramming in the early mammalian embryo. Current Opinions in Genetics and Development 34 17-23. (https://doi. org/10.1016/j.gde.2015.06.003)

Bolton H, Graham SJL, Van der Aa N, Kumar P, Theunis K, Fernandez Gallardo E, Voet T \& Zernicka-Goetz M 2016 Mouse model of chromosome mosaicism reveals lineage-specific depletion of aneuploid cells and normal developmental potential. Nature Communications 7 11165. (https://doi.org/10.1038/ncomms11165)

Cai KQ, Capo-Chichi CD, Rula ME, Yang DH \& Xu XX 2008 Dynamic GATA6 expression in primitive endoderm formation and maturation in early mouse embryogenesis. Developmental Dynamics 237 2820-2829. (https://doi.org/10.1002/dvdy.21703)

Campbell A \& Fishel S 2015 Atlas of Time Lapse Embryology. Boca Raton, London, New York: Taylor \& Francis Group, CRC Press.

Campbell K \& Swann K 2006 Ca2+ oscillations stimulate an ATP increase during fertilization of mouse eggs. Developmental Biology 298 225-233. (https://doi.org/10.1016/j.ydbio.2006.06.032)

Catteeuw M, Wydooghe E, Mullaart E, Knijn HM \& Van Soom A 2017 In vitro production of bovine embryos derived from individual donors in the Corral $(\mathbb{R}$ dish. Acta Veterinaria Scandinavica 59 41. (https://doi. org/10.1186/s13028-017-0309-9)

Cetinkaya M, Pirkevi C, Yelke H, Colakoglu YK, Atayurt Z \& Kahraman S 2015 Relative kinetic expressions defining cleavage synchronicity are better predictors of blastocyst formation and quality than absolute time points. Journal of Assisted Reproduction and Genetics 32 27-35. (https://doi.org/10.1007/s10815-014-0341-x)

Chavez SL, Loewke KE, Han J, Moussavi F, Colls P, Munne S, Behr B \& Reijo Pera RA 2012 Dynamic blastomere behaviour reflects human embryo ploidy by the four-cell stage. Nature Comminications 31251. (https://doi.org/10.1038/ncomms2249)

Chazaud C, Yamanaka Y, Pawson T \& Rossant J 2006 Early lineage segregation between epiblast and primitive endoderm in mouse 
blastocysts through the Grb2-MAPK pathway. Developmental Cell 10 615-624. (https://doi.org/10.1016/j.devcel.2006.02.020)

Cockburn K \& Rossant J 2010 Making the blastocyst: lessons from the mouse. Journal of Clinical Investigation 120 995-1003. (https://doi. org/10.1172/JCl41229)

Conaghan J, Chen AA, Willman SP, Ivani K, Chenette PE, Boostanfar R, Baker VL, Adamson GD, Abusief ME, Gvakharia M et al. 2013 Improving embryo selection using a computer-automated time-lapse image analysis test plus day 3 morphology: results from a prospective multicenter trial. Fertility and Sterility 100 412.e5-419.e5. (https://doi. org/10.1016/j.fertnstert.2013.04.021)

Cruz M, Gadea B, Garrido N, Pedersen KS, Martinez M, Perez-Cano I, Munoz M \& Meseguer M 2011 Embryo quality, blastocyst and ongoing pregnancy rates in oocyte donation patients whose embryos were monitored by time-lapse imaging. Journal of Assisted Reproduction and Genetics 28 569-573. (https://doi.org/10.1007/s10815-011-9549-1)

Cruz M, Garrido N, Herrero J, Perez-Cano I, Munoz M \& Meseguer M 2012 Timing of cell division in human cleavage-stage embryos is linked with blastocyst formation and quality. Reproductive Biomedicine Online 25 371-381. (https://doi.org/10.1016/j.rbmo.2012.06.017)

Dalcin L, Silva RC, Paulini F, Silva BD, Neves JP \& Lucci CM 2013 Cytoskeleton structure, pattern of mitochondrial activity and ultrastructure of frozen or vitrified sheep embryos. Cryobiology 67 137-145. (https://doi.org/10.1016/j.cryobiol.2013.05.012)

D'Avino PP, Giansanti MG \& Petronczki M 2015 Cytokinesis in animal cells. Cold Spring Harbor Perspectives in Biology 7 a015834. (https://doi. org/10.1101/cshperspect.a015834)

Ducibella T, Schultz RM \& Ozil JP 2006 Role of calcium signals in early development. Seminars in Cell and Developmental Biology 17 324-332. (https://doi.org/10.1016/j.semcdb.2006.02.010)

Dumollard R, Marangos P, Fitzharris G, Swann K, Duchen M \& Carroll J 2004 Sperm-triggered $[\mathrm{Ca} 2+]$ oscillations and $\mathrm{Ca} 2+$ homeostasis in the mouse egg have an absolute requirement for mitochondrial ATP production. Development 131 3057-3067. (https://doi.org/10.1242/ dev.01181)

Findikli N \& Oral E 2014 Time-lapse embryo imaging technology: does it improve the clinical results? Current Opinion in Obstetrics and Gynecology 26 138-144. (https://doi.org/10.1097/GCO.0000000000000072)

Flach G, Johnson MH, Braude PR, Taylor RA \& Bolton VN 1982 The transition from maternal to embryonic control in the 2-cell mouse embryo. EMBO Journal 1 681-686.

Fraser L 1982 Ca2+ is required for mouse sperm capacitation and fertilization in vitro. Journal of Andrology 3 412-419. (https://doi. org/10.1002/j.1939-4640.1982.tb00712.x)

Fulton BP \& Whittingham DG 1978 Activation of mammalian oocytes by intracellular injection of calcium. Nature 273 149-151. (https://doi. org/10.1038/273149a0)

Goodman LR, Goldberg J, Falcone T, Austin C \& Desai N 2016 Does the addition of time-lapse morphokinetics in the selection of embryos for transfer improve pregnancy rates? A randomized controlled trial. Fertility and Sterility 105 275.e10-285.e10. (https://doi.org/10.1016/j. fertnstert.2015.10.013)

Hendriks WK, Roelen BA, Colenbrander B \& Stout TA 2015 Cellular damage suffered by equine embryos after exposure to cryoprotectants or cryopreservation by slow-freezing or vitrification. Equine Veterinary Journal 47 701-707. (https://doi.org/10.1111/evj.12341)

Herrero J \& Meseguer M 2013 Selection of high potential embryos using time-lapse imaging: the era of morphokinetics. Fertility and Sterility $\mathbf{9 9}$ 1030-1034. (https://doi.org/10.1016/j.fertnstert.2013.01.089)

Hosu BG, Mullen SF, Critser JK \& Forgacs G 2008 Reversible disassembly of the actin cytoskeleton improves the survival rate and developmental competence of cryopreserved mouse oocytes. PLOS ONE 3 e2787. (https://doi.org/10.1371/journal.pone.0002787)

Kieslinger DC, De Gheselle S, Lambalk CB, De Sutter P, Kostelijk EH, Twisk JW, van Rijswijk J, van den Abbeel E \& Vergouw CG 2016 Embryo selection using time-lapse analysis (Early Embryo Viability Assessment) in conjunction with standard morphology: a prospective two-center pilot study. Human Reproduction 31 2450-2457. (https://doi.org/10.1093/ humrep/dew207)

Kirkegaard K, Hindkjaer JJ, Grøndahl ML, Kesmodel US \& Ingerslev HJ 2012 A randomized clinical trial comparing embryo culture in a conventional incubator with a time-lapse incubator. Journal of Assisted
Reproduction and Genetics 29 565-572. (https://doi.org/10.1007/ s10815-012-9750-x)

Kirkegaard K, Kesmodel US, Hindkjaer JJ \& Ingerslev HJ 2013 Time-lapse parameters as predictors of blastocyst development and pregnancy outcome in embryos from good prognosis patients: a prospective cohort study. Human Reproduction 28 2643-2651. (https://doi.org/10.1093/ humrep/det300)

Kirkegaard K, Ahlstrom A, Ingerslev HJ \& Hardarson T 2015 Choosing the best embryo by time lapse versus standard morphology. Fertility and Sterility 103 323-332. (https://doi.org/10.1016/j.fertnstert.2014.11.003)

Kojima Y, Tam OH \& Tam PP 2014 Timing of developmental events in the early mouse embryo. Seminars in Cell and Developmental Biology 34 65-75. (https://doi.org/10.1016/j.semcdb.2014.06.010)

Kulíková B, Jiménez-Trigos E, Makarevich AV, Chrenek P, Vicente JS \& Marco-Jiménez F 2016 State of actin cytoskeleton and development of slow-frozen and vitrified rabbit pronuclear zygotes. Cryobiology $\mathbf{7 2}$ 14-20. (https://doi.org/10.1016/j.cryobiol.2015.11.009)

Li L, Lu X \& Dean J 2013 The maternal to zygotic transition in mammals. Molecular Aspects of Medicine 34 919-938. (https://doi.org/10.1016/j. mam.2013.01.003)

Luciano AM, Chigioni S, Lodde V, Franciosi F, Luvoni GC \& Modina SC 2009 Effect of different cryopreservation protocols on cytoskeleton and gap junction mediated communication integrity in feline germinal vesicle stage oocytes. Cryobiology 59 90-95. (https://doi.org/10.1016/j. cryobiol.2009.05.002)

Martelli AM, Zweyer M, Ochs RL, Tazzari PL, Tabellini G, Narducci P \& Bortul R 2001 Nuclear apoptotic changes: an overview. Journal of Cellular Biochemistry 82 634-646. (https://doi.org/10.1002/jcb.1186)

Meseguer M, Herrero J, Tejera A, Hilligsoe KM, Ramsing NB \& Remohi J 2011 The use of morphokinetics as a predictor of embryo implantation. Human Reproduction 26 2658-2671. (https://doi.org/10.1093/humrep/ der256)

Meseguer M, Rubio I, Cruz M, Basile N, Marcos J \& Requena A 2012 Embryo incubation and selection in a time-lapse monitoring system improves pregnancy outcome compared with a standard incubator: a retrospective cohort study. Fertility and Sterility 98 1481-1489. (https:// doi.org/10.1016/j.fertnstert.2012.08.016)

Milewski R \& Ajduk A 2017 Time-lapse imaging of cleavage divisions in embryo quality assessment. Reproduction 154 R37-R53. (https://doi. org/10.1530/REP-17-0004)

Milewski R, Kuć P, Kuczyńska A, Stankiewicz B, Łukaszuk K \& Kuczyński W 2015 A predictive model for blastocyst formation based on morphokinetic parameters in time-lapse monitoring of embryo development. Journal of Assisted Reproduction and Genetics 32 571579. (https://doi.org/10.1007/s10815-015-0440-3)

Milewski R, Czerniecki J, Kuczyńska A, Stankiewicz B \& Kuczyński W 2016a Morphokinetic parameters as a source of information concerning embryo developmental and implantation potential. Ginekologia Polska 87 677-684. (https://doi.org/10.5603/GP.2016.0067)

Milewski R, Milewska AJ, Kuczyńska A, Stankiewicz B \& Kuczyński W 2016b Do morphokinetic data sets inform pregnancy potential? Journal of Assisted Reproduction and Genetics 33 357-365. (https://doi. org/10.1007/s10815-016-0649-9)

Morris SA, Guo Y \& Zernicka-Goetz M 2012 Developmental plasticity is bound by pluripotency and the Fgf and Wnt signaling pathways. Cell Reports 2 756-765. (https://doi.org/10.1016/j.celrep.2012.08.029)

Motato Y, de los Santos MJ, Escriba MJ, Ruiz BA, Remohi J \& Meseguer M 2016 Morphokinetic analysis and embryonic prediction for blastocyst formation through an integrated time-lapse system. Fertility and Sterility 105 376.e9-384.e9. (https://doi.org/10.1016/j. fertnstert.2015.11.001)

Nakahara T, Iwase A, Goto M, Harata T, Suzuki M, lenaga M, Kobayashi H, Takikawa S, Manabe S, Kikkawa F et al. 2010 Evaluation of the safety of time-lapse observations for human embryos. Journal of Assisted Reproduction and Genetics 27 93-96. (https://doi.org/10.1007/s10815010-9385-8)

Ombelet W, De Sutter P, Van der Elst J \& Martens G 2005 Multiple gestation and infertility treatment: registration, reflection and reactionthe Belgian project. Human Reproduction Update 11 3-14. (https://doi. org/10.1093/humupd/dmh048)

Ozil JP, Markoulaki S, Toth S, Matson S, Banrezes B, Knott JG, Schultz RM, Huneau D \& Ducibella T 2005 Egg activation events are regulated by the 
duration of a sustained [Ca2+]cyt signal in the mouse. Developmental Biology 282 39-54. (https://doi.org/10.1016/j.ydbio.2005.02.035)

Ozil JP, Banrezes B, Toth S, Pan H \& Schultz RM 2006 Ca2+ oscillatory pattern in fertilized mouse eggs affects gene expression and development to term. Developmental Biology 300 534-544. (https://doi.org/10.1016/j. ydbio.2006.08.041)

Polanski LT, Coelho Neto MA, Nastri CO, Navarro PA, Ferriani RA, Raine-Fenning N \& Martins WP 2014 Time-lapse embryo imaging for improving reproductive outcomes: systematic review and meta-analysis. Ultrasound in Obstetrics and Gynecology 44 394-401. (https://doi. org/10.1002/uog.13428)

Pribenszky C, Matyas S, Kovacs P, Losonczi E, Zadori J \& Vajta G 2010 Pregnancy achieved by transfer of a single blastocyst selected by timelapse monitoring. Reproductive Biomedicine Online 21 533-536. (https://doi.org/10.1016/j.rbmo.2010.04.015)

Racowsky C, Kovacs P \& Martins WP 2015 A critical appraisal of timelapse imaging for embryo selection: where are we and where do we need to go? Journal of Assisted Reproduction and Genetics 32 1025-1030. (https://doi.org/10.1007/s10815-015-0510-6)

Rubio I, Galan A, Larreategui Z, Ayerdi F, Bellver J, Herrero J \& Meseguer M 2014 Clinical validation of embryo culture and selection by morphokinetic analysis: a randomized, controlled trial of the EmbryoScope. Fertility and Sterility 102 1287-1294. (https://doi. org/10.1016/j.fertnstert.2014.07.738)

de los Santos MJ, Arroyo G, Busquet A, Calderon G, Cuadros J, Hurtado de Mendoza MV, Moragas M, Herrer R, Ortiz A, Pons C et al. 2014 A multicenter prospective study to assess the effect of early cleavage on embryo quality, implantation, and live-birth rate. Fertility and Sterility 101 981-987. (https://doi.org/10.1016/j.fertnstert.2013.12.043)

Saiz N, Grabarek JB, Sabherwal N, Papalopulu N \& Plusa B 2013 Atypical protein kinase $C$ couples cell sorting with primitive endoderm maturation in the mouse blastocyst. Development 140 4311-4322. (https://doi. org/10.1242/dev.093922)

Saunders KM \& Parks JE 1999 Effects of cryopreservation procedures on the cytology and fertilization rate of in vitro-matured bovine oocytes. Biology of Reproduction 61 178-187. (https://doi.org/10.1095/ biolreprod61.1.178)

Sfontouris IA, Kolibianakis EM, Lainas GT, Venetis CA, Petsas GK, Tarlatzis BC \& Lainas TG 2017 Blastocyst utilization rates after continuous culture in two commercial single-step media: a prospective randomized study with sibling oocytes. Journal of Assisted Reproduction and Genetics 34 1377-1383. (https://doi.org/10.1007/s10815-0170997-0)

Siristatidis C, Komitopoulou MA, Makris A, Sialakouma A, Botzaki M, Mastorakos G, Salamalekis G, Bettocchi S \& Palmer GA 2015 Morphokinetic parameters of early embryo development via time lapse monitoring and their effect on embryo selection and ICSI outcomes: a prospective cohort study. Journal of Assisted Reproduction and Genetics 32 563-570. (https://doi.org/10.1007/s10815-015-0436-z)

Strumpf D, Mao CA, Yamanaka Y, Ralston A, Chawengsaksophak K, Beck F \& Rossant J 2005 Cdx2 is required for correct cell fate specification and differentiation of trophectoderm in the mouse blastocyst. Development 132 2093-2102. (https://doi.org/10.1242/dev.01801)

Sun QY \& Schatten H 2006 Regulation of dynamic events by microfilaments during oocyte maturation and fertilization. Reproduction 131 193-205. (https://doi.org/10.1530/rep.1.00847)

Sveen JK 2004 An introduction to MatPIV v.1.6.1. In eprint series. Mechanics and Applied Mathematics 2 (ISSN 0809-4403). (Available at: http://folk.uio.no/jks/matpiv) (2004).
Swann K, Windsor S, Campbell K, Elgmati K, Nomikos M, ZernickaGoetz M, Amso N, Lai FA, Thomas A \& Graham C 2012 Phospholipase C-zeta induced $\mathrm{Ca}(2+)$ oscillations cause coincident cytoplasmic movements in human oocytes that failed to fertilize after intracytoplasmic sperm injection. Fertility and Sterility 97 742-747. (https://doi. org/10.1016/j.fertnstert.2011.12.013)

Tamassia M, Heyman Y, Lavergne Y, Richard C, Gelin V, Renard JP \& Chastant-Maillard S 2003 Evidence of oocyte donor cow effect over oocyte production and embryo development in vitro. Reproduction 126 629-637. (https://doi.org/10.1530/rep.0.1260629)

Toth S, Huneau D, Banrezes B \& Ozil JP 2006 Egg activation is the result of calcium signalsummation in the mouse. Reproduction 131 27-34. (https://doi.org/10.1530/rep.1.00764)

Vanden Berghe T, Grootjans S, Goossens V, Dondelinger Y, Krysko DV, Takahashi N \& Vandenabeele P 2013 Determination of apoptotic and necrotic cell death in vitro and in vivo. Methods 61 117-129. (https:// doi.org/10.1016/j.ymeth.2013.02.011)

Vázquez-Diez C, Yamagata K, Trivedi S, Haverfield J \& FitzHarris G 2016 Micronucleus formation causes perpetual unilateral chromosome inheritance in mouse embryos. PNAS 113 626-631. (https://doi. org/10.1073/pnas.1517628112)

Vera-Rodriguez M, Chavez SL, Rubio C, Reijo Pera RA \& Simon C 2015 Prediction model for aneuploidy in early human embryo development revealed by single-cell analysis. Nature Communications 67601. (https://doi.org/10.1038/ncomms8601)

VerMilyea MD, Tan L, Anthony JT, Conaghan J, Ivani K, Gvakharia M, Boostanfar R, Baker VL, Suraj V, Chen AA et al. 2014 Computerautomated time-lapse analysis results correlate with embryo implantation and clinical pregnancy: a blinded, multicentre study. Reproductive Biomedicine Online 29 729-736. (https://doi.org/10.1016/j. rbmo.2014.09.005)

Walker MC, Murphy KE, Pan S, Yang Q \& Wen SW 2004 Adverse maternal outcomes in multifetal pregnancies. BJOG 111 1294-1296. (https://doi. org/10.1111/j.1471-0528.2004.00345.x)

Weinerman R, Feng R, Ord TS, Schultz RM, Bartolomei MS, Coutifaris C \& Mainigi M 2016 Morphokinetic evaluation of embryo development in a mouse model: functional and molecular correlates. Biology of Reproduction 94 1-7. (https://doi.org/10.1095/biolreprod.115.136119)

Wong CC, Loewke KE, Bossert NL, Behr B, De Jonge CJ, Baer TM \& Reijo Pera RA 2010 Non-invasive imaging of human embryos before embryonic genome activation predicts development to the blastocyst stage. Nature Biotechnology 28 1115-1121. (https://doi.org/10.1038/ nbt.1686)

Yang ST, Shi JX, Gong F, Zhang SP, Lu CF, Tan K, Leng LZ, Hao M, He H, Gu YF et al. 2015 Cleavage pattern predicts developmental potential of day 3 human embryos produced by IVF. Reproductive Biomedicine Online 30 625-634. (https://doi.org/10.1016/j.rbmo.2015.02.008)

Zernicka-Goetz M, Morris SA \& Bruce AW 2009 Making a firm decision: multifaceted regulation of cell fate in the early mouse embryo. Nature Reviews Genetics 10 467-477. (https://doi.org/10.1038/nrg2564)

Received 19 April 2017

First decision 10 may 2017

Revised manuscript received 4 October 2017

Accepted 9 October 2017 